\title{
La política española de inmigración y los intereses económicos de España en el extranjero
}

\author{
Rosa María Verdugo-Matés
}

Universidad de Santiago de Compostela, España

Resumen

A partir de la década de 1990 España comienza a perfilarse como un país de inmigración, de forma que, considerando los 15 países de la Unión Europea, en el año 2008 España es el que registra un mayor número de extranjeros. La importancia creciente de España como destino de las migraciones internacionales fue utilizada por el gobierno español para diseñar una política migratoria que favoreció la internacionalización de las empresas españolas. Durante el periodo 2000-2005, la política migratoria facilitó la llegada de latinoamericanos al territorio español y, al mismo tiempo, la entrada de Inversión Extranjera Directa española en América Latina. Posteriormente, a partir del año 2006, la política migratoria se centró en la externalización del control de los flujos a través de la firma de acuerdos migratorios con diferentes países africanos que, como contrapartida, vieron incrementada la Ayuda Oficial al Desarrollo española en sus países.

Palabras clave: Migraciones; Política migratoria; Inversión Extranjera Directa; Ayuda Oficial al Desarrollo.

\section{Abstract}

\section{Spanish migration policy and the Spanish economic interests abroad}

In the 1990s Spain emerged as an immigration country, becoming in 2008 the second country with the highest number of foreigners in the 15-member European Union. The increasing importance of Spain as the destination for international migrations was used by the Spanish government to design a migration policy that favoured the internationalization of Spanish companies. During the period 2000-2005, the migration policy facilitated the entrance of Latin Americans to the Spanish territory and, simultaneously, the entrance of Spanish Foreign Direct Investment in Latin America. Subsequently, since 2006, the migration policy focused on the externalisation of the control of migration flows through the signature of migration agreements with different African countries where the Official Development Assistance was increased.

Key words: Migrations, Migrations policy, Foreign Direct Investment, Official Development Assistance 


\section{INTRODUCCIÓN}

7 ras la finalización de la Segunda Guerra Mundial los movimientos migratorios internacionales se han intensificado, siendo el proceso especialmente intenso desde la última década del siglo XX. Según datos de la estadística Trends in International Migrant Stock de las Naciones Unidas, en 1990 había 154 millones de migrantes internacionales, aumentando su número hasta 221 millones en 2010 (United Nations, 2013). La importancia creciente de los flujos migratorios ha generado el interés de investigadores de diferentes áreas de conocimiento, publicándose numerosos trabajos donde se analizan aspectos muy diversos de las migraciones internacionales.

En el ámbito de la economía, se han publicado trabajos que analizan las repercusiones de las migraciones internacionales, tanto en las economías de destino como en las economías de origen de los migrantes. En relación a su impacto en las economías de destino, la gran mayoría de las investigaciones destacan el aporte positivo de los migrantes en las economías receptoras: hay autores que concluyen que los inmigrantes contribuyen positivamente al crecimiento económico (Moreno y Bruquetas, 2011; Verdugo et al., 2015), otros señalan que los inmigrantes son contribuyentes netos a las cuentas del Estado (Aparicio, 2002), y otros indican que los inmigrantes inciden en la reducción del desempleo estructural y en el aumento de la tasa de actividad femenina (Sebastián, 2006). Por lo que respecta a su contribución en las economías de origen, la mayoría de los trabajos se han centrado en la repercusión de la llegada de remesas a los países de origen de los migrantes, pero los resultados obtenidos por los diferentes investigadores son divergentes: unos autores han resaltado el impacto positivo de las remesas en las economías receptoras señalando que proporcionan divisas y ahorros adicionales para el desarrollo económico (Kapur, 2005), mientras que otros autores advierten que las remesas pueden perpetuar la dependencia económica y socavar las perspectivas de desarrollo de las economías que las reciben (Chami et al., 2003).

El objetivo de este artículo es analizar para el caso español un aspecto aun no investigado en el ámbito de las migraciones internacionales y la economía: la relación entre la política migratoria española y los intereses económicos de España en el exterior. Para ello estructuramos el artículo de la siguiente forma. En primer lugar, analizamos el papel de los países del sur de Europa en las migraciones internacionales, como emisores de emigrantes después de la Segunda Guerra Mundial y como receptores de inmi- 
grantes desde la década de 1990. A continuación, nos centramos en el caso español, analizando los cambios cuantitativos y cualitativos experimentados en los residentes extranjeros desde la década de 1990: aumento del número de inmigrantes y latinoamericanización de los flujos migratorios. Posteriormente, relacionamos este proceso con la preferencia que tienen los españoles por este colectivo de extranjeros frente a otros. Para finalizar, vinculamos la política migratoria española con los intereses económicos de las empresas españolas en el extranjero, aportando datos que develan que el gobierno español ha utilizado la política migratoria para favorecer la internacionalización de las empresas españolas.

\section{LOS PAÍSES DEL SUR DE EUROPA: DE EMISORES DE EMIGRANTES}

\section{A RECEPTORES DE INMIGRANTES}

Tras la finalización de la Segunda Guerra Mundial se produce una reactivación económica sin precedentes en los países del centro y norte de Europa, de forma que en el período 1950-1973 la variación anual media del Producto Interior Bruto (PIB) fue de 4.6 por ciento y la del PIB per cápita de 3.8 por ciento. En ese mismo periodo, en estos países se concluye la transición demográfica, lo que se tradujo en una desaceleración del crecimiento de su población, que registró una variación anual media de 0.3 por ciento (Crafts y Toniolo, 1996). En este contexto económico y demográfico, la demanda de trabajo superó a la oferta interna, por lo que estas economías se vieron obligadas a recurrir al empleo de trabajadores extranjeros que, en gran medida, llegaron de los países del sur de Europa, fundamentalmente de España, Grecia, Italia y Portugal (Seers, 1981), donde el crecimiento económico era mucho más moderado y el crecimiento poblacional más elevado. ${ }^{1}$

Desde el punto de vista económico estos flujos migratorios fueron beneficiosos tanto para los países receptores como para los emisores. Por una parte, en los países receptores se alcanzaron tasas de crecimiento económico que no hubieran sido posibles sin el aporte de esta fuerza de trabajo extranjera, que además ocupó los peores puestos de trabajo favoreciendo el ascenso laboral de los autóctonos. Por otra parte, en los países emisores

\footnotetext{
${ }^{1}$ El premio nobel de economía Gary S. Becker vinculó la transición demográfica al proceso de crecimiento económico. Según este autor, en los países donde se culmina la I Revolución Industrial también se da un cambio en las pautas demográficas de su población: reducción de la tasa de fecundidad y, como resultado, desaceleración del crecimiento de la población (Becker, 1960).
} 
se alivió la situación de desempleo y subempleo y se utilizó la llegada de remesas para impulsar el proceso de industrialización. ${ }^{2}$

Este modelo de crecimiento económico entró en crisis tras el alza de los precios del petróleo del año 1973. En este nuevo contexto, los países del centro y norte de Europa empezaron a registrar unas elevadas y crecientes tasas de desempleo, lo que interrumpió la demanda de fuerza de trabajo extranjera. Además, el desempleo afectó más duramente a los extranjeros, de forma que estos países comenzaron a poner en marcha políticas de retorno y a endurecer la legislación que regulaba la entrada, la permanencia y el trabajo de los extranjeros (Mármora, 2002: 284-295).

Las economías capitalistas europeas sólo mostraron signos de recuperación a mediados de la década de 1980. Pero una vez superada la coyuntura de crisis no se volvieron a producir flujos migratorios intra-europeos tan voluminosos como los registrados en la etapa anterior. Por una parte, en los países del norte y centro de Europa la tasa de crecimiento económico fue más moderada que la registrada en la etapa de posguerra, lo que influyó negativamente en la demanda de trabajadores extranjeros. Por otra parte, en los países del sur de Europa se experimentaron cambios económicos, políticos y sociales que favorecieron la permanencia de los autóctonos. En el ámbito económico, la entrada de Grecia en la Comunidad Económica Europea (CEE) en el año 1981 y la incorporación de España y Portugal en 1986, canalizó una importante cantidad de fondos estructurales hacia estas economías, lo que incidió positivamente sobre su crecimiento económico y creación de empleo. En el ámbito político-social, la finalización de la dictadura portuguesa y griega en 1974 y de la española en 1975 abrieron expectativas de cambio a los autóctonos: democratización y puesta en marcha de un Estado del Bienestar similar al existente en el resto de los países europeos capitalistas.

A comienzos de la década de 1990 se inicia una fase recesiva en la economía mundial, que será seguida de una nueva fase de crecimiento a partir de 1995. En esta nueva fase, las economías del sur de Europa registran las tasas de crecimiento más elevadas y las del norte y centro europeo las más bajas. En concreto, durante el período 1995-2008 la economía irlandesa fue la que tuvo la mayor tasa de crecimiento anual acumulativa, en concreto de diez por ciento, seguida de la griega (7.6 por ciento) y de la española (6.9 por ciento), mientras que la menor tasa se registró en la economía alemana

\footnotetext{
${ }^{2}$ Por ejemplo, Gyltsos (2002) calculó el impacto de las remesas sobre la renta en cinco países del mediterráneo (Egipto, Grecia, Jordán, Marruecos y Portugal) y concluyó que, en un período de seis años, la inversión aumentó en una cantidad mayor que el monto de la transferencia inicial en cuatro países.
} 
(1.9 por ciento). ${ }^{3} \mathrm{Al}$ mismo tiempo, la finalización de la transición demográfica en los países del sur de Europa, con la consiguiente desaceleración en el crecimiento de su población, provocó que la oferta de trabajo interna no fuera suficiente para cubrir las necesidades de la demanda de trabajo de sus economías, por lo que estos países necesitaron recurrir al empleo de fuerza de trabajo extranjera, convirtiéndose en los principales receptores de inmigrantes de la UE-15 (Barou, 2006). Según datos de la estadística Eurostat de la Comisión Europea, durante el período 1995-2008 el número de residentes extranjeros en la UE-15 pasó de 17.5 a 29.2 millones, un incremento de 11.7 millones, de los cuales 8.4 millones se concentraron en los países del sur de Europa (España, Grecia, Italia y Portugal) (Tabla 1).

En los países del sur de Europa el trabajo de los inmigrantes se vio favorecido por varios factores, como la consolidación de mercados de trabajo segmentados o el relativamente elevado peso de la economía informal, elementos que facilitaron el empleo de los inmigrantes indocumentados (López Sala, 2005). Otro factor que favoreció la llegada de inmigrantes a los países del sur de Europa fue la existencia de una legislación en materia de extranjeros que era más permisiva con la entrada, la permanencia y el trabajo de los extranjeros que la existente en los países del norte y centro de Europa. Así, mientras que los países europeos de tradición inmigratoria comenzaban a construir el espacio Schengen en $1985^{4}$ para restringir la inmigración en sus territorios, la poca presencia de extranjeros en los países del sur de Europa provocaba que estos mantuvieran una legislación de extranjería bastante laxa, aunque esta situación cambiará a medida que el número de extranjeros se incrementa. Además, la proximidad geográfica del sur de Europa con los nuevos focos emisores de emigrantes (países africanos y del este de Europa) y los vínculos históricos con los actuales países emisores de emigrantes (en el caso español con América Latina, en el caso portugués con Brasil y las antiguas colonias africanas) aceleraron la llegada de inmigrantes.

\footnotetext{
${ }^{3}$ Los cálculos de las tasas anuales acumulativas se han realizado a partir de los datos del PIB que figuran en la estadística Eurostat (Comisión Europea).

${ }^{4}$ En el año 1985, Alemania, Francia, Bélgica, Países Bajos y Luxemburgo, firmaron el Acuerdo de Schengen, embrión de la Política Común de Inmigración de la Unión Europea (UE). Su objetivo era eliminar las barreras interiores entre los países firmantes para favorecer la circulación de personas en el interior de sus fronteras y, al mismo tiempo, reforzar sus fronteras exteriores para restringir la entrada de extranjeros extra-comunitarios.
} 
Tabla 1: Número de extranjeros en la UE-15

\begin{tabular}{lrrrr}
\hline & \multicolumn{1}{c}{1995} & \multicolumn{1}{c}{2008} & $\begin{array}{r}\text { Incremento } \\
\text { en número }\end{array}$ & $\begin{array}{r}\text { Incremento } \\
\text { en porcentaje }\end{array}$ \\
\hline Alemania & 7173900 & 7255395 & 81495 & 1.1 \\
Austria & 677061 & 824974 & 147913 & 21.8 \\
Bélgica & 909769 & 971448 & 61679 & 6.8 \\
Dinamarca & 222746 & 298450 & 75704 & 34.0 \\
España & 542314 & 5262095 & 4719781 & 870.3 \\
Finlandia & 68566 & 132708 & 64142 & 93.5 \\
Francia & 3411371 & 3709814 & 298443 & 8.7 \\
Grecia & 155453 & 906400 & 750947 & 483.1 \\
Irlanda & 114311 & 559021 & 444710 & 389.0 \\
Italia & 729159 & 3432651 & 2703492 & 370.8 \\
Luxemburgo & 138050 & 205889 & 67839 & 49.1 \\
Países Bajos & 725400 & 688375 & -37025 & -5.1 \\
Portugal & 168316 & 446333 & 278017 & 165.2 \\
Reino Unido & 1948000 & 4020800 & 2072800 & 106.4 \\
Suecia & 531797 & 524488 & -7309 & -1.4 \\
Sur de Europa & 1595242 & 10047479 & 8452237 & 529.8 \\
UE-15 & 17516213 & 29238841 & 11722628 & 66.9 \\
\hline
\end{tabular}

Fuente: elaboración propia a partir de datos de Eurostat (Comisión Europea).

\section{LA CONSOLIDACIÓN DE ESPAÑa COMO PAÍS DE INMIGRACIÓN}

Desde la segunda mitad de la década de 1980 y hasta la llegada de la crisis actual, se produce una fase de crecimiento en la economía mundial. En el caso español, este crecimiento se vio ampliado por su incorporación a la CEE en 1986. Efectivamente, la entrada española a la Europa comunitaria favoreció la expansión de determinados cultivos agrícolas, en concreto los mediterráneos, por lo que en las regiones mediterráneas se creó un elevado número de puestos de trabajo en este sector. Las características de estos empleos agrícolas (alta temporalidad, baja remuneración, largas y duras jornadas de trabajo) provocaron que los autóctonos se emplearan en otras ocupaciones con mejores condiciones salariales y laborales, de forma que los empresarios agrícolas tuvieron que recurrir a la contratación de trabajadores extranjeros. Así, según datos del Ministerio de Empleo y Seguridad 
Social en el año 1999 había 86 mil extranjeros en alta laboral en el Sistema Especial Agrario, incrementándose su número hasta 532 mil en 2010, de forma que durante ese período más de 25 por ciento de las altas laborales de los extranjeros se registraron en este sector.

Otro sector económico que se vio favorecido por la incorporación de España a la Europa comunitaria fue el de la construcción. Tras la adhesión, la CEE canalizó una importante cantidad de fondos estructurales que se destinaron, en gran medida, a la realización de obras de infraestructuras, lo que aumentó el número de empleos en el sector de la construcción. Además, el modelo de crecimiento español, centrado desde mediados de la década de 1990 en la especulación inmobiliaria, también contribuyó a acelerar la creación de puestos de trabajo en este sector, siendo muchos de ellos ocupados por extranjeros. De hecho, según los datos de la Encuesta de la Población Activa (EPA) del Instituto Nacional de Estadística (INE), durante el período 1996-2004 el número de ocupados en la construcción aumentó en un millón, de los cuales 400 mil fueron extranjeros.

A partir de mediados de la década de 1990 comienza a notarse la desaceleración en el incremento de la población activa española, consecuencia de la finalización de la transición demográfica, por lo que para poder desarrollar su crecimiento potencial España tendrá que recurrir al empleo de trabajadores extranjeros. De hecho, durante el período 1995-2008, España fue el país de la UE-15 que más aumentó su población extranjera: en 1995 residían en el territorio español poco más de medio millón de extranjeros y en 2008 la cifra superaba los 5 millones, ${ }^{5}$ convirtiéndose en el segundo país con más extranjeros de la UE-15, solo por detrás de Alemania (Tabla 1). Estos cambios cuantitativos fueron acompañados de otros de tipo cualitativo. Hasta el año 2000 los marroquíes eran la primera nacionalidad de extranjeros (200 mil), superando en número al conjunto de nacionalidades de América Latina. Sin embargo, en menos de una década, los latinoamericanos incrementan su presencia, de forma que en el año 2008 se registran 1.3 millones de latinoamericanos y 700 mil marroquíes (Figura 1).

Esta evolución es el resultado de la aplicación por parte del gobierno español de una política migratoria que favoreció la entrada y el trabajo de los latinoamericanos basándose en la existencia de vínculos históricos, culturales y lingüísticos con América Latina.

${ }^{5}$ La llegada de la crisis en el año 2008 va a desacelerar y posteriormente disminuir la entrada la de inmigrantes: el número de extranjeros alcanza su máximo en 2010 con 5.4 millones, pero en 2013 la cifra es de cinco millones. 


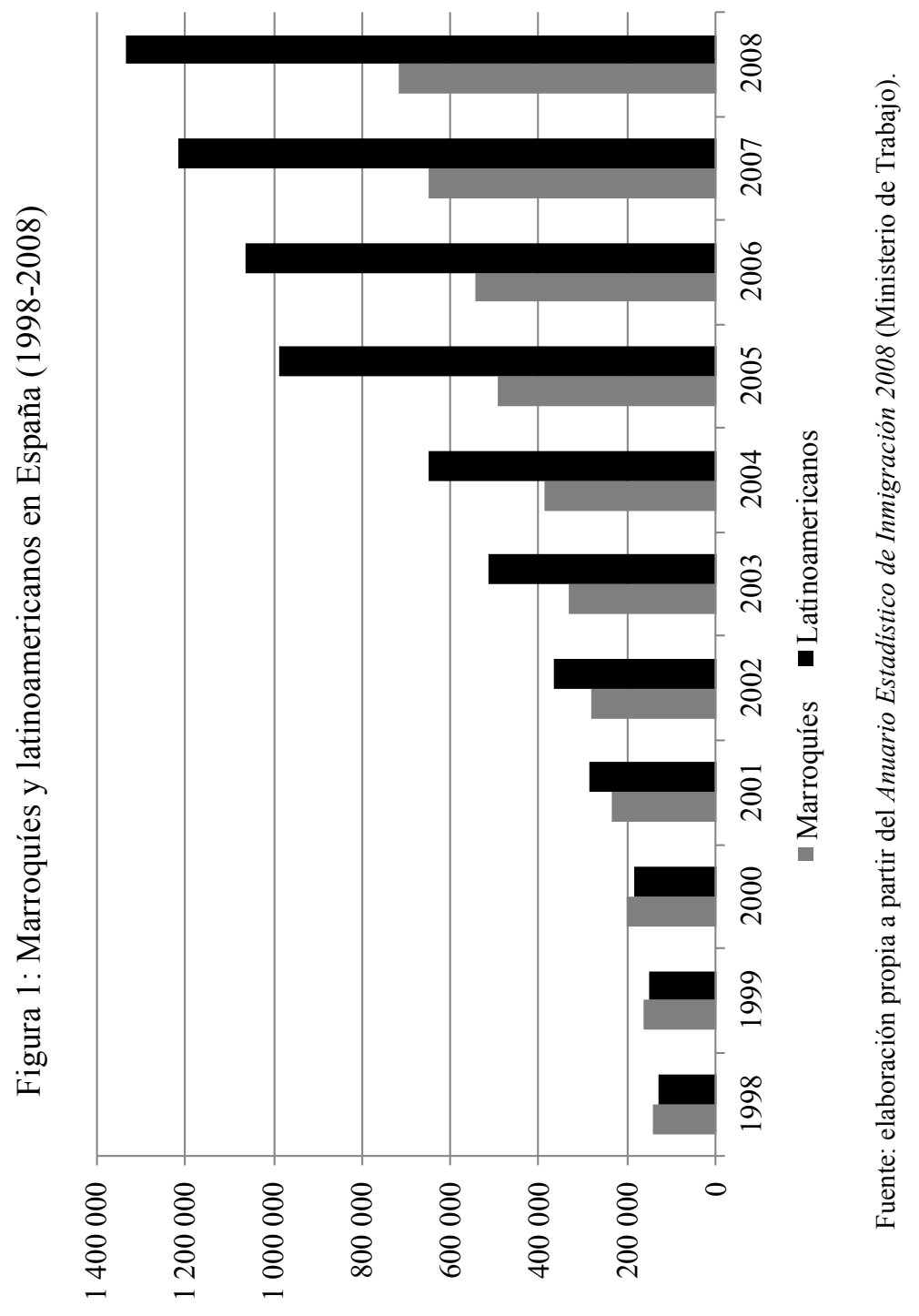


La aplicación de medidas de discriminación positiva a favor de este colectivo no tuvo importantes detractores en una sociedad española que manifiesta explícitamente su preferencia por este colectivo de extranjeros frente a otros, sobre todo frente a los marroquíes, que eran hasta el año 2000 la nacionalidad más numerosa. Sin ser el único factor explicativo, el rechazo de los españoles hacia los marroquíes ha sido potenciado por los medios de comunicación, que han difundido un perfil negativo de la inmigración, ofreciendo imágenes donde predomina un perfil del inmigrante que concuerda con la del extranjero de origen marroquí (Granados, 2004).

Tomando como referencia la Teoría del Sistema Mundo (Wallerstein, 1974), Sassen analiza para el periodo 1960-1985 la relación entre la llegada de migrantes a Estados Unidos y el papel de las empresas estadounidenses en el extranjero, concluyendo que la internacionalización ha contribuido a la formación y dirección de la migración de trabajadores (Sassen, 1988). Como veremos a lo largo de este artículo, desde la década de 1990 el contingente de trabajadores extranjeros en España se ha incrementado, destacando la llegada de colectivos procedentes de aquellos países en los que las empresas españolas han llevado a cabo su proceso de internacionalización, validando en gran medida la Teoría del Sistema Mundo.

\section{LA PREFERENCIA ESPAÑOLA POR LOS LATINOAMERICANOS}

Los resultados de diferentes encuestas realizadas por el Centro de Investigaciones Sociológicas (CIS) indican que los españoles prefieren a los latinoamericanos frente a otros extranjeros. En el barómetro de noviembre de 2003 del CIS, se valoró la simpatía y la confianza que tienen los españoles por los ciudadanos de diferentes países. ${ }^{6}$ Los más valorados fueron los argentinos: el 73.5 por ciento de los entrevistados respondió tener mucha o bastante simpatía por este colectivo y 60 por ciento afirmó tener mucha o bastante confianza en ellos. Y los segundos más valorados fueron los mexicanos, seguidos de los brasileños, ambos con valores muy cercanos a los argentinos. En el otro extremo, los menos valorados fueron los marroquíes: únicamente 33.7 por ciento de los entrevistados afirmaron tener mucha o bastante simpatía por este grupo y solo 26.6 por ciento dijo tener en ellos mucha o bastante confianza.

Otros datos también indican indirectamente esta preferencia. En una encuesta elaborada por el CIS en 2008, se solicita a los entrevistados que valoren la importancia de diferentes aspectos que se deberían tener en

\footnotetext{
${ }^{6}$ CIS: Barómetro noviembre 2003 (preguntas 18 y 19).
} 
cuenta para permitir a una persona extranjera venir a España. ${ }^{7}$ En una escala de 0 a 10, la opción "que hable castellano o la lengua de esta Comunidad Autónoma" fue valorada entre nueve y diez por 21 por ciento de los encuestados y entre siete y ocho por 27 por ciento. También se les solicitó que valoraran el hecho de que en la sociedad española existan personas de diferentes países, culturas, religiones y razas. ${ }^{8}$ En una escala de cero a diez, el aspecto peor valorado fue la existencia de diferentes religiones, de forma que 10.6 por ciento lo valoró entre cero y uno y 11.3 por ciento entre dos y tres.

Posiblemente, la preferencia de los españoles por los latinoamericanos está relacionada con la existencia de lazos históricos, culturales y lingüísticos comunes, de forma que los nacionales de estos países son vistos como "más próximos" o "menos extranjeros" que otros colectivos. De hecho, en una encuesta elaborada por el CIS en 2010, 72.9 por ciento de los entrevistados respondió que los iberoamericanos tienen menos dificultades que otros extranjeros para integrarse en la sociedad española. ${ }^{9}$ Para el profesor Antonio Izquierdo, los motivos de esta mayor aceptación se asienta en varios frentes. Por una parte, en los motivos de su venida a España: los españoles no les ven únicamente como trabajadores necesitados, sino que perciben que entre ellos también hay profesionales, directivos y trabajadores cualificados, es decir, clases medias con las que las relaciones son más fáciles. Por otra parte, se piensa que muchos vienen por razones afectivas tales como el matrimonio y las relaciones familiares, lo que aumenta su simpatía. Sin embargo, tal vez esta preferencia también tenga como finalidad anular la dependencia de la mano de obra marroquí en la agricultura y la construcción, así como eludir el choque cultural con otra religión (Izquierdo et al., 2002). De hecho, para los empresarios españoles el perfil idóneo de los trabajadores extranjeros sería el de "hombres o mujeres jóvenes, aunque casados y con hijos; provenientes de zonas rurales y, dentro de éstas, de estrato socioeconómico bajo; de ciertos países de origen, considerados afines culturalmente al contexto español en cuanto a lenguaje, religión y costumbres" (Sánchez-Montijano y Faúndez-García, 2011: 60).

Esta preferencia de la sociedad española por los latinoamericanos legitimó al gobierno español a desarrollar medidas para favorecer la presencia de este colectivo, tal y como podemos constatar tras analizar la evolución de los permisos de trabajo concedidos. Como decíamos anteriormente, en la última fase de crecimiento económico en la economía española el

\footnotetext{
${ }^{7}$ CIS: Actitudes hacia la inmigración, septiembre-octubre 2008 (pregunta 6).

${ }^{8}$ CIS: Actitudes hacia la inmigración, septiembre-octubre 2008 (pregunta 10).

${ }^{9}$ CIS: Cooperación y América Latina, octubre 2010 (pregunta 37).
} 
aumento de la demanda de trabajo superó a la oferta de trabajo interna. Por ese motivo, la Ley Orgánica de Extranjería (LOE) del año 2000 creó el sistema del contingente, es decir, la contratación de los extranjeros en origen para cubrir las demandas empresariales. En los primeros años tras la aprobación de la LOE, América Latina destaca entre las regiones más beneficiadas por el contingente, de forma que, de los siete primeros acuerdos concluidos, tres fueron con países latinoamericanos: Colombia, Ecuador y República Dominicana. Estos acuerdos iniciales se emprendieron con países con los que la migración ya formaba parte del diálogo bilateral (como en Colombia), o se utilizaron precisamente como vía para abrir dicho diálogo (como en Ecuador), pero con el pretexto de selección basada en criterios culturales (Ferrero y López, 2009). El sistema del contingente aceleró la llegada de latinoamericanos, tal y como indica la evolución del número de permisos de trabajo concedidos: en el año 1999, 40 por ciento del total de permisos de trabajo concedidos se concentraban en los marroquíes y algo menos de 30 por ciento en los latinoamericanos, pero a partir del año 2002 los marroquíes solo acumulaban en torno a 15 por ciento y los latinoamericanos sobrepasaban 50 por ciento de los permisos de trabajo concedidos (Figura 2).

A continuación, veremos que durante el último período de expansión económica la política migratoria aperturista española fue aprovechada por el gobierno español para ofrecer en los países latinoamericanos una visón generosa del país (Tedesco, 2010), lo que tuvo una influencia positiva en la política exterior con América Latina, fundamentalmente en la internacionalización de las empresas españolas en la región.

\section{LOS INTERESES ECONÓMICOS DE ESPAÑa EN EL EXTRANJERO}

A pesar de la progresiva emergencia de una política de inmigración común en la UE, una de las dimensiones más determinantes (la gestión de la admisión de la inmigración económica) permanece en gran medida en manos de los estados miembros que van a diseñar sus políticas migratorias teniendo en cuenta los intereses de su política exterior. Precisamente, esa relación es la que explica que las políticas de inmigración tengan un componente importante de discrecionalidad o que legitimen diferencias de trato entre individuos motivadas por su nacionalidad. ${ }^{10}$

${ }^{10}$ El estabelecimiento de derechos y deberes recíprocos a través de tratados internacionales fue considerado como una "justificación razonable" para un tratamiento diferenciado de los extranjeros por el Comité de Derechos Humanos (Comunicación nº 658/1995). 


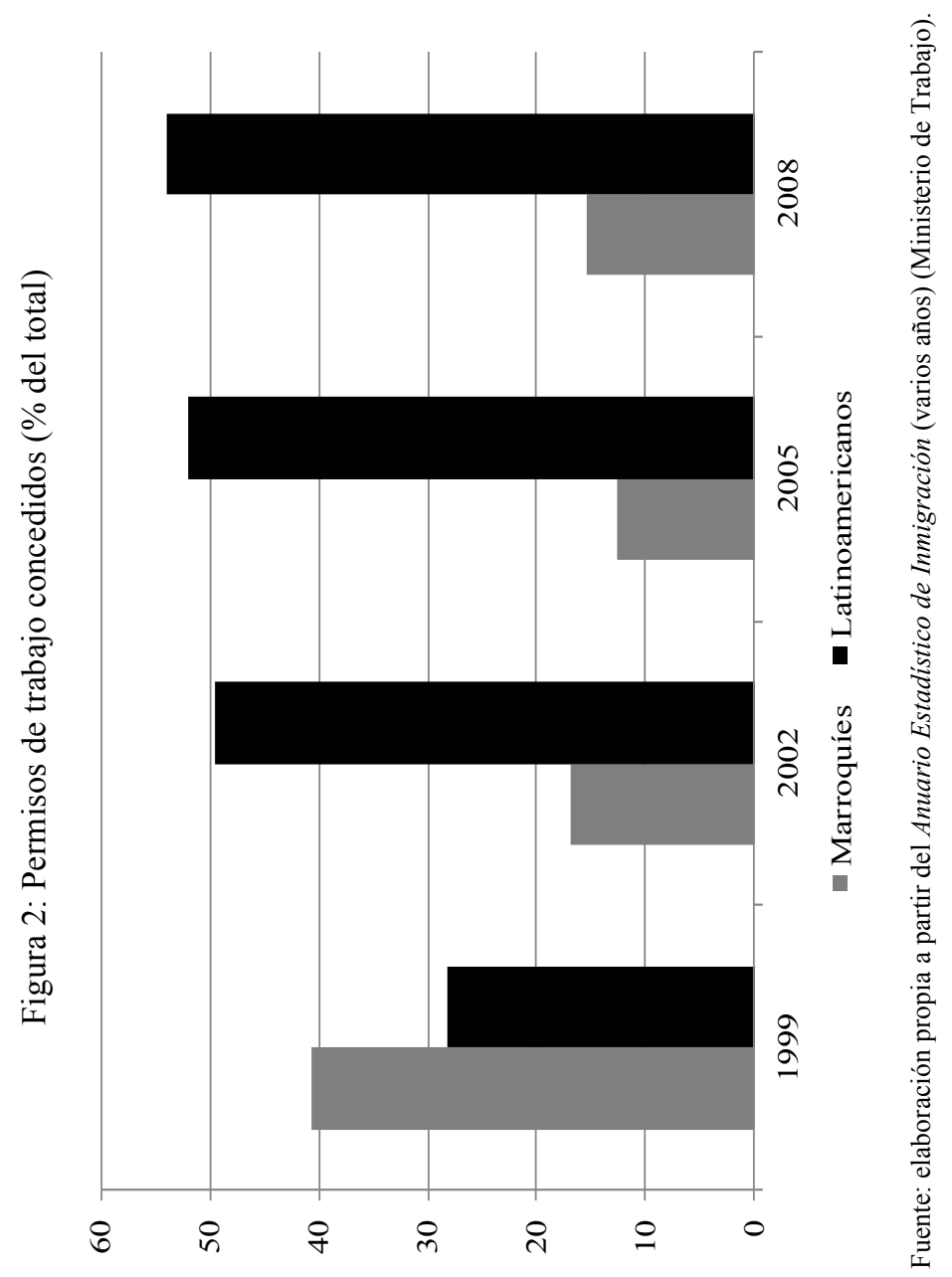


De esta forma, el pasado colonial, las afinidades culturales o lingüísticas y los intereses geoestratégicos y económicos van a manifestarse en la elaboración de la política de inmigración en los diferentes países de la UE. Como ya han puesto de manifiesto otros investigadores, la importancia de América Latina en las relaciones exteriores españolas tiene sus raíces en lazos históricos, culturales y lingüísticos, pero también en intereses económicos (Del Arenal, 1994).

En la segunda mitad de la década de 1990 se inicia una nueva fase de crecimiento en los países del centro del capitalismo mundial. En ese momento, muchos países de América Latina llevan a cabo procesos de privatización, liberalización y desregularización de sus economías, procesos que formaban parte de las Políticas de Ajuste Estructural (PAE) impuestas por el Fondo Monetario Internacional (FMI) y el Banco Mundial (BM) como solución a la denominada "crisis de la deuda". Los procesos de privatización intensificaron la atracción de Inversión Extranjera Directa (IED) en actividades de telecomunicaciones, energía eléctrica, prospección, explotación y distribución de petróleo y derivados, agua y gas. Por su parte, las medidas de liberalización y desregulación otorgaron un tratamiento muy favorable a la inversión extranjera en actividades del sector servicios, en especial de las financieras.

Todos estos elementos operaron como factores de atracción (factores pull) de la inversión española, justo en un momento en el que las empresas españolas ponían en marcha una estrategia de ampliación de mercados desarrollando ventajas de propiedad e internacionalización (factores push). La combinación de los factores de atracción e impulso es la que explica la intensa salida de la inversión española hacia América Latina (Arahuetes y García, 2007). Así, al final de la década de 1990 España se situó entre las ocho economías del mundo por su cantidad de inversión en el extranjero, ocupando el segundo puesto de país inversor en América Latina, solo por detrás de los Estados Unidos. Sin embargo, la situación cambiará en el año 2000, debido a la desaceleración de la economía estadounidense y a las bajas expectativas de crecimiento de los países de la UE y Japón. Como resultado, se produce una reducción de las fusiones y adquisiciones transfronterizas y, por lo tanto, de los flujos internacionales de inversión. En 2003 se inicia una nueva fase de crecimiento en la economía mundial y con ella se reactiva la inversión, pero en este período el destino principal de la inversión española serán los países de la UE-15 (Arahuetes y García, 2007). Aun así, América Latina siguió teniendo una importancia crucial para la inversión española. Los datos de la estadística Bilateral Statistics de la UNCTAD nos muestran como durante el período 2003-2012, 25 por ciento del total de stock de inversión española en el extran- 
jero se concentró en América Latina (Figura 3), reafirmándose España en la región como el primer inversor europeo y el segundo mundial.

Figura 3: Stock de IED española en América Latina (\% del total)

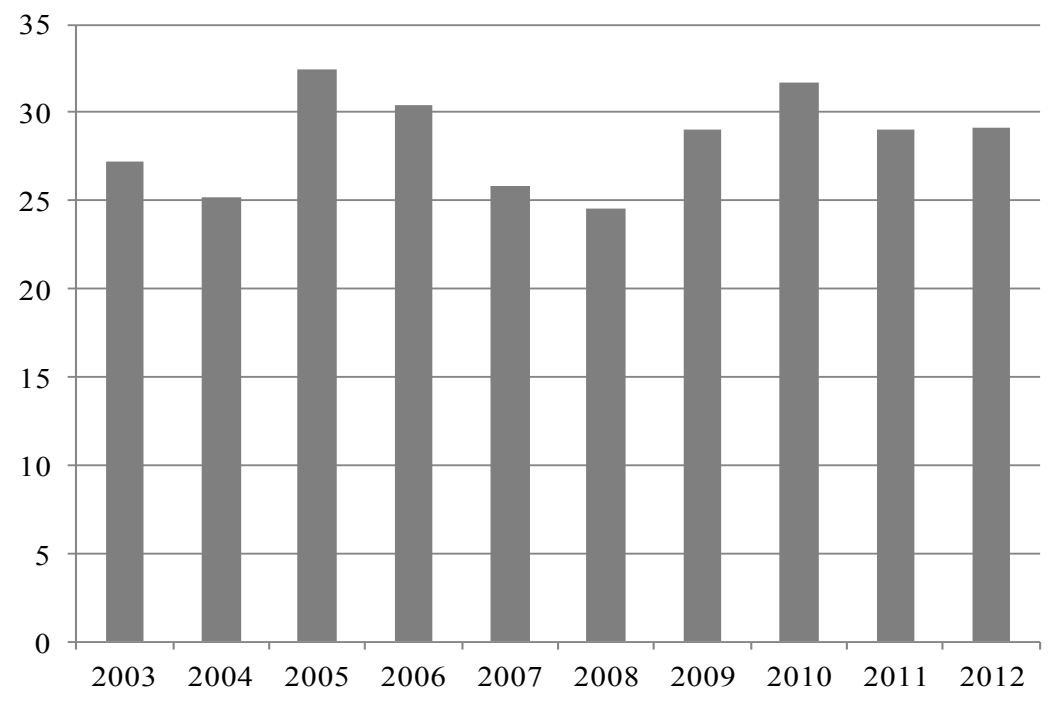

Fuente: elaboración propia a partir de datos de Bilateral Statistics (UNCTAD).

Seguramente la expansión de las empresas españolas en América Latina se vio facilitada por los vínculos históricos, culturales y lingüísticos entre España estos países. Además, el gobierno español utilizó dos instrumentos para potenciar esta expansión: los acuerdos bilaterales en materia de migración y la Ayuda Oficial al Desarrollo (AOD). Por lo que respecta a los acuerdos bilaterales, anteriormente vimos que, durante la última fase de crecimiento económico, y en especial en el período 2000-2005, el gobierno español favoreció la entrada de los latinoamericanos con este instrumento de política migratoria. En el año 2001 España firmó acuerdos migratorios con Colombia, República Dominicana, Ecuador y Marruecos. De esta forma, durante el periodo 2000-2005 los trabajadores extranjeros en España aumentaron un 271 por ciento, mientras que los colombianos se incrementaron 976 por ciento y los ecuatorianos 951 por ciento. Sin embargo, por motivos que posteriormente veremos, los marroquíes solo aumentaron 136 por ciento, muy por debajo de la media (Tabla 2). 
La política española de inmigración y los intereses económicos de España en el extranjero /R. M. VERDUGO-MATÉS

Tabla 2: Evolución del número de trabajadores extranjeros en España según procedencia

\begin{tabular}{lrrrrrr}
\hline & Total & América & Colombia & $\begin{array}{r}\text { Rep. } \\
\text { Dominicana }\end{array}$ & Ecuador & Marruecos \\
\hline 2000 & 454571 & 105171 & 12101 & 12327 & 25729 & 101809 \\
2001 & 607074 & 177625 & 26814 & 13208 & 67879 & 124223 \\
2002 & 831658 & 293072 & 60468 & 14622 & 125667 & 148051 \\
2003 & 925280 & 325764 & 62869 & 15873 & 132956 & 158328 \\
2004 & 1076744 & 390027 & 77673 & 18672 & 147196 & 172664 \\
2005 & 1688598 & 690418 & 130173 & 25317 & 270326 & 239941 \\
Incremento (núm.) & 1234027 & 585247 & 118072 & 12990 & 244597 & 138132 \\
Incremento (\%) & $271 \%$ & $556 \%$ & $976 \%$ & $105 \%$ & $951 \%$ & $136 \%$ \\
\hline
\end{tabular}

Fuente: elaboración propia a partir de datos del Ministerio de Trabajo.

Aunque durante el periodo 1993-2006, el 86 por ciento de los flujos de inversión española hacia América Latina se concentraron en Argentina, Brasil, México y Chile (Arahuetes y García, 2007), a partir del año 2000 la inversión española cobra importancia para algunos países de América Latina, y más concretamente para aquellos con los que España estableció acuerdos bilaterales en materia de migración, como Ecuador, Colombia y República Dominicana. Los datos de la estadística Bilateral FDI Statistic de la UNCTAD nos muestran que en el año 2011 en Ecuador más de 35 por ciento del stock de inversión era de origen español, siendo el porcentaje superior a 30 por ciento en Colombia y en Bolivia y superior a 20 por ciento en Argentina y República Dominicana (Figura $4^{11}$ ).

Además de los acuerdos bilaterales en materia de migración, la ayuda al desarrollo también ha cumplido su papel de favorecer la expansión de la inversión española en América Latina. El propio Ministerio de Asuntos Exteriores y Cooperación así lo indica en el Plan Director de Cooperación 2005-2008 cuando presenta la Ley de Cooperación Internacional como el marco adecuado para establecer la relación que deben tener la política de cooperación, la política exterior y la política comercial. Es más, el Plan reconoce "la influencia de intereses comerciales y geoestratégicos" en la extensión y sistematización de la ayuda a América Latina a partir de la década de 1980 (Ministerio de Asuntos Exteriores y Cooperación, 2005: 16).

\footnotetext{
${ }^{11}$ Para medir la importancia que tiene la inversión española en los diferentes países de América Latina podemos recurrir a la estadística Bilateral FDI Statistic de la UNCTAD, ya que en ella se registra para cada país del mundo las entradas y el stock de inversión y se indica el país de procedencia de la inversión. Aunque la estadística se inicia en el año 2001, para algunos países latinoamericanos no se publicó la información todos los años, por lo que hemos tenido que escoger el ano 2011.
} 
Figura 4: \% Instock español en el total instock de cada país (año 2011)

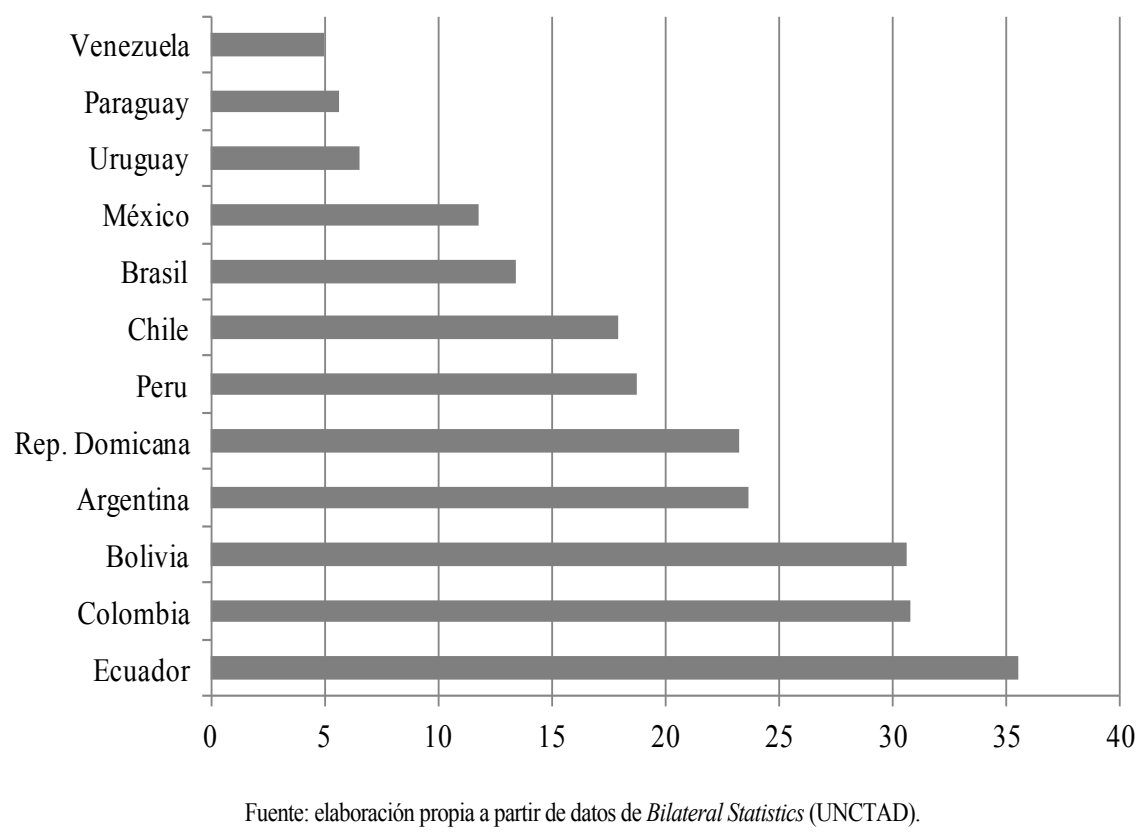

Por lo tanto, no es casualidad que la ayuda al desarrollo española en América Latina se intensifique justo a partir de la segunda mitad de la década de 1990, momento en el que la inversión española iniciaba su expansión en la región. Los datos de la OCDE nos muestran que desde finales de la década de 1980, la ayuda al desarrollo española es inferior a cinco por ciento del total de los países de la Comisión de Ayuda al Desarrollo (CAD), pero su participación en América Latina es de diez por ciento a comienzos de la década de 1990, de 15 por ciento en 2001 y de más de 25 por ciento en 2008 (Figura 5).

Sin embargo, los asaltos a las vallas de Ceuta y Melilla en 2005 y la crisis de los cayucos en 2006, redefinieron las prioridades de la política migratoria española, situando a África en el punto de mira (Pinyol, 2007) y, al mismo tiempo, reorientando las prioridades de política exterior por primera vez hacia esta región (Asín, 2008). Tras la Conferencia Euroafricana de Rabat sobre Migración y Desarrollo de 2006, se consolidó el modelo de Acuerdos de Cooperación Migratoria en África, y se puso en funcionamiento el I Plan el África (20062009), que será seguido por el II Plan el África (20092012). 
Figura 5: AOD española por regiones de destino ( $\%$ de los países de la CAD)

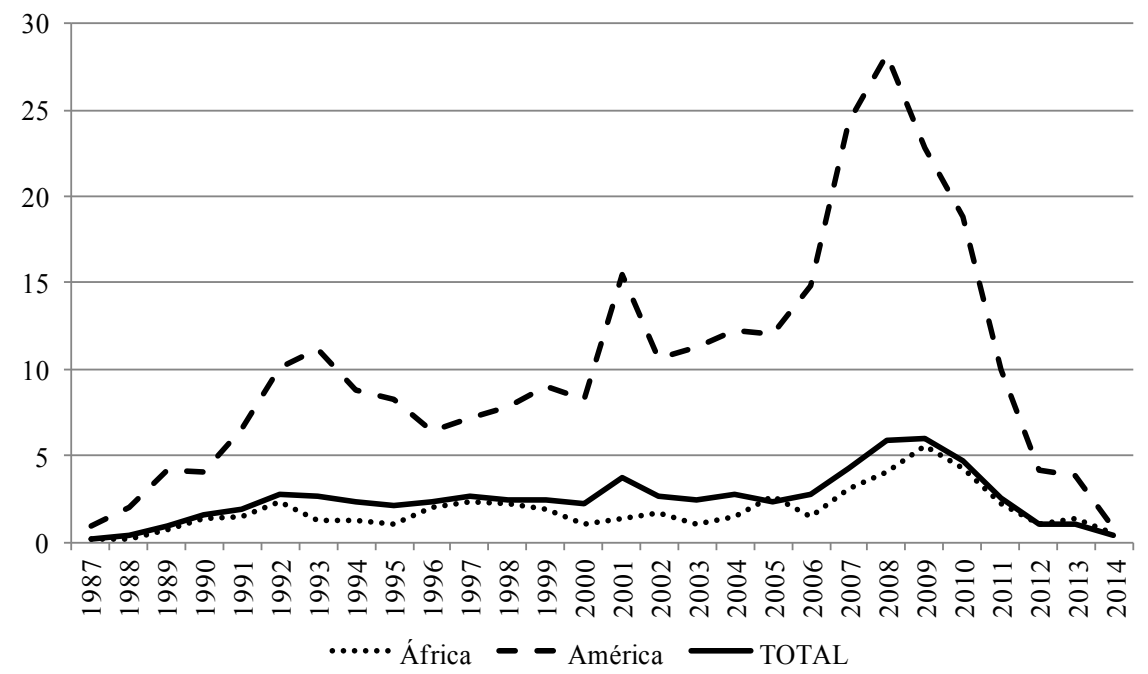

Fuente: elaboración propia a partir de datos de la OCDE.

Estos Planes tienen dos vertientes: por una parte, la cooperación al desarrollo $\mathrm{y}$, por otra, la cooperación en materia migratoria (fundamentalmente control de fronteras y repatriación). Estas dos vertientes se inscriben en el marco de las políticas de inmigración de la UE basadas en la firma de acuerdos migratorios que tienen como finalidad la externalización del control de los flujos migratorios hacia terceros países que son origen o tránsito de las migraciones hacia Europa, y muy especialmente con los del continente africano. Como contrapartida, los países europeos se comprometen a incrementar la inversión y la ayuda al desarrollo en los países que firmen los acuerdos migratorios (Gabrielli, 2012: 54).

En relación al control de fronteras, para el gobierno español estos planes fueron un éxito, de forma que si en el año 2006, 35 mil clandestinos llegaron por vía marítima, en 2012 solo lo hicieron 4 mil. Ahora bien, es importante señalar que las salidas del continente africano no se han frenado, sino que los migrantes han buscado rutas alternativas y más peligrosas para evitar los dispositivos de control, lo que ha incrementado el número de muertes en el mar. Por lo que respecta a la ayuda al desarrollo española, esta aumentó en aquellos países que colaboraron con el control de las fronteras. Desde el año 2007 el porcentaje de ayuda al desarrollo española en África aumenta y desde 2011 sobrepasa el porcentaje destinado a América (Figura 6). 
Figura 6: Distribución porcentual de la AOD española por regiones (1987-2014)

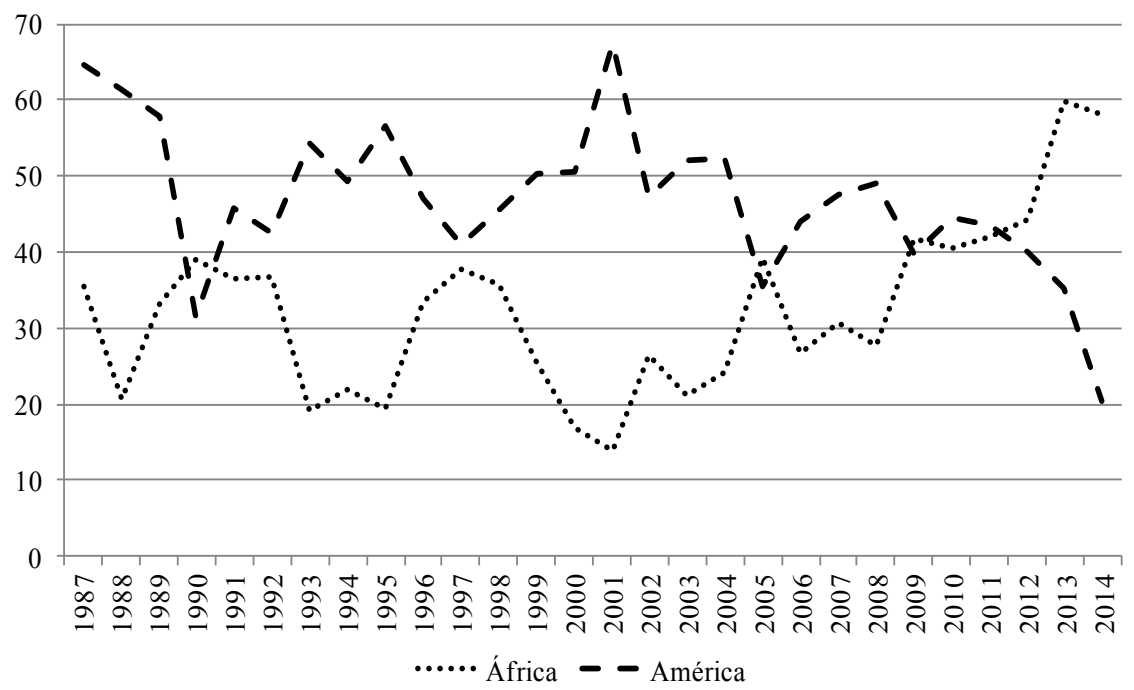

Fuente: elaboración propia a partir de datos de la OCDE.

Pero igual que sucedió en América Latina, en África la política migratoria española fue aprovechada para favorecer los intereses económicos de las empresas españolas en el extranjero. De una forma directa, el I Plan África manifiesta sus intereses económicos en el continente. En el documento "Plan África 2006-2008. Resumen ejecutivo", el Ministerio de Asuntos Exteriores y Cooperación incluye los siete objetivos del Plan. El quinto dice textualmente:

"El refuerzo y la diversificación de los intercambios económicos, así como el fomento de las inversiones, sin olvidar la creciente importancia estratégica de la región subsahariana, y en particular el Golfo de Guinea, para nuestra seguridad energética y las oportunidades de negocio en el sector de hidrocarburos para las empresas españolas".

Efectivamente, el Plan da prioridad a la creación de empresas mixtas y a la participación de empresas españolas (como Repsol-YPF) en el sector energético en países como Angola, Gabón, Guinea o Nigeria. Además, el Plan también da prioridad a la renegociación de los acuerdos de pesca en Namibia, Mozambique o Sudáfrica, países donde algunas multinacionales 
españolas (como Pescanova) ya tenían intereses en materia de pesca. Todos estos países están incluidos en el Plan como países de interés prioritario. ${ }^{12}$

La vinculación entre la ayuda al desarrollo española en África y los intereses económicos españoles en la región también quedan patentes cuando comparamos las prioridades establecidas en el I Plan África y las oportunidades de negocio anunciadas en los informes de la Oficina Económica y Comercial de España en Dakar. Por ejemplo, si en el plan se prioriza la construcción de infraestructuras como uno de los objetivos de la ayuda al desarrollo, en el informe se resalta la oportunidad para la venta de material de construcción dada la gran cantidad de obras públicas con financiación internacional. ${ }^{13}$ Dentro de la ayuda al desarrollo, uno de los instrumentos que más ha favorecido a los empresarios españoles son los créditos del Fondo de Ayuda al Desarrollo (FAD). Se trata de créditos de ayuda al desarrollo de forma ligada, ya que el país receptor tiene que realizar la devolución del mismo comprando bienes y servicios al donante. En teoría, se trata de contribuir al desarrollo económico y social de los países receptores y, al mismo tiempo, de promover la internacionalización de la economía española, dos objetivos que algunos investigadores han demostrado incompatibles (Arias, 2005). De hecho, algunos autores que han analizado la repercusión de los créditos FAD indican que su aplicación da lugar a la denominada "paradoja del enriquecimiento del donante" (González y Larrú, 2004), por lo que no cumplen su función de contribuir al desarrollo de los países que los reciben.

A pesar de que el gobierno español considera compatible la defensa de los intereses económicos españoles en África y el desarrollo del continente, la experiencia nos muestra otra realidad. Así, tal y como ya ha puesto de manifiesto otras investigaciones, el Plan África se dirige a países y sectores en función de su potencial y atractivo para los empresarios españoles, pero sin valorar en ningún momento su incidencia en el desarrollo de los países africanos (Alberdi y Bidaurratzaga, 2008: 207). ${ }^{14}$ Otras investigaciones denuncian que la expansión de las multinacionales españolas en África ha contribuido a agravar la pobreza en el continente

${ }^{12}$ Países de interés prioritario, que responden a varios de los objetivos señalados: Guinea Ecuatorial, Senegal, Malí y Nigeria en África Central y Occidental; Angola, Namibia, Sudáfrica y Mozambique en África Austral; y Kenia y Etiopía en África Oriental. También se incluye a Mauritania por su importancia estratégica y su condición de país bisagra entre el Magreb y África occidental.

${ }^{13}$ Este y otros ejemplos pueden verse en Romero: 2008, p.171-172.

${ }^{14}$ Esta misma idea se manifiesta en el documento de Intermón-OXFAM titulado La Realidad de la Ayuda 2006-2007 donde se afirma: "La atención a criterios de tipo comercial, de inversión y geoestratégicos que incorpora el Plan África pueden ser legítimos desde el punto de vista de la política exterior española, pero no necesariamente ayudan a los objetivos de desarrollo de África subsahariana" (Intermón-OXFAM, 2006: 98). 
(Romero, 2008: 162). A título indicativo, la sobreexplotación de los barcos europeos (mayoritariamente españoles) en Senegal sobreexplotaron los caladeros y repercutieron negativamente sobre la pesca artesanal, avocando a muchos pescadores artesanales senegaleses hacia la emigración (Verdugo y Villasante: 2012). En definitiva, la ayuda al desarrollo se ha utilizado como moneda de cambio en la negociación del control migratorio, y no como un instrumento capaz de reducir los flujos actuando sobre sus causas, lo que provoca el riesgo de "desviación" de las finalidades de la ayuda al desarrollo (Gabrielli, 2012: 55).

\section{Conclusiones}

A mediados de la década de 1990 se inicia una fase de crecimiento en la economía mundial. Dentro de la UE-15 la economía española se situó entre las que consiguieron las mayores tasas de crecimiento económico y de creación de empleo. Al mismo tiempo, y como consecuencia de la transición demográfica, el crecimiento de la población activa española comenzó a desacelerarse, por lo que el gobierno español abrió la puerta a la contratación de trabajadores extranjeros para desarrollar su crecimiento económico potencial.

Por su proximidad geográfica, hasta la década de 1990 los marroquíes eran el principal colectivo de extranjeros en el territorio español. Sin embargo, a partir del año 2000 la necesidad de fuerza de trabajo extranjera fue cubierta con nacionales de países de América Latina. La preferencia de los españoles por los latinoamericanos legitimó al gobierno español a poner en marcha una política migratoria que favoreció las entradas de este colectivo. Alegando vínculos históricos, culturales y lingüísticos, el gobierno español aprovechó para dar en América Latina una visión generosa del país, pero en realidad utilizó esta política migratoria para reforzar la expansión de la inversión española en la región.

Posteriormente, a partir del año 2006, y bajo el pretexto de la fuerte afluencia de inmigrantes subsaharianos a las costas españolas, España, al igual que el resto de los países de la Europa comunitaria, pone en marcha una política migratoria de exteriorización de fronteras, que implica la colaboración de los países africanos en el control de sus fronteras a cambio de un aumento de la ayuda al desarrollo. Para ello el gobierno español pone en marcha el Plan África, que se traduce en un aumento de la ayuda al desarrollo en aquellos países que lleven a cabo un control de sus fronteras. Sin embargo, lejos de contribuir al desarrollo de los países receptores, la ayuda al desarrollo se convirtió en un nuevo instrumento para favorecer los intereses de las empresas españolas en el exterior. 
Ahora bien, la política migratoria de externalización de fronteras conlleva riesgos importantes. Por una parte, se corre el riesgo de desvirtuar la ayuda al desarrollo, que debería dirigirse a los países más pobres, y que pueden no coincidir con los países de origen y tránsito de los flujos migratorios. Por otra parte, se corre el riesgo de apoyar a gobiernos poco o nada democráticos a cambio de la gestión del control de los flujos migratorios, algo que ya ha ocurrido en la cooperación europea con Túnez o Libia (Gabrielli, 2012: 55).

Teóricamente, la inversión extranjera y la ayuda al desarrollo son dos instrumentos que los países desarrollados pueden utilizar para favorecer el crecimiento económico en los países en vías de desarrollo. Sin embargo, la realidad es muy diferente. Así, y tal y como se ha puesto de manifiesto en este artículo y en otras investigaciones (Alberdi y Bidaurratzaga, 2008; Arias, 2005; Romero, 2008), la llegada de inversión extranjera y de ayuda al desarrollo a los países del Sur ha contribuido al empobrecimiento de sus economías, al tiempo que se han aumentado los beneficios de las empresas de los países del Norte.

\section{REFERENCIAS BIBLIOGRÁFICAS}

Alberdi Bidaguren, Jokin y Bidaurratzaga Aurre, Eduardo, 2008, "La nueva política exterior y de cooperación de España con el continente africano. El asociacionismo interesado del Plan África", en Revista CIDOB d'Afers Internacionals, núm. 84.

Aparicio Gómez, Rosa, 2002, "El impacto económico de la inmigración: costes para el Estado y movimiento de consumos y salarios", en Cuadernos de trabajo social, núm. 15.

Arahuetes García, Alfredo y García Domonte, Aurora, 2007, ¿Qué ha sucedido con la Inversión Extranjera Directa (IED) de las empresas españolas en América Latina tras el boom de los años noventa y la incertidumbre de los primeros años 2000?, Documento de Trabajo núm.35/2007, Real Instituto Elcano, Madrid.

Arias Alba Marta, 2005, "Créditos FAD: el debate que nunca llega", en Economía exterior: estudios de la revista Política Exterior sobre la internacionalización de la economía española, núm. 35.

Asín Cabrera, $\mathrm{M}^{\mathrm{a}}$ Asunción, 2008, "Tratados internacionales recientes en materia de inmigración concluidos con países de África occidental", en La Inmigración en la encrucijada, Anuario de la Inmigración en España, Centre d'Informació i Documentació Internacionals de Barcelona, Barcelona.

Barou, Jacques, 2006, "Les pays du Suds et de l'Est de l'Europe, nouvelle porte d'entrée", en Europe, terre d'immigration: Flux migratoires et intégration. Grenoble: Presses Universitaires de Grenoble, Grenoble. 
Becker, Gary S., 1960, “An Economic Analysis of Fertility”, en Demographic and Economic Change in Developed Countries, N.J. Princeton University Press, Princeton.

Centro de Investigaciones Sociológicas (CIS), 2003, Barómetro de noviembre, estudio núm. 2.545, disponible en http://www.cis.es/cis/opencm/ES/11_barometros/ depositados.jsp, consultado el 5/03/2016.

Centro de Investigaciones Sociológicas (CIS), 2008, Actitudes hacia la inmigración (II), estudio núm. 2.773, septiembre-octubre, disponible en http://www. cis.es/cis/opencm/ES/1_encuestas/estudios/ver.jsp?estudio=9680, consultado el $5 / 03 / 2016$.

Centro de Investigaciones Sociológicas (CIS), 2010, Cooperación y América Latina (VI), estudio núm. 2.845, septiembre, http://www.cis.es/cis/opencm/ES/1_encuestas/estudios/ver.jsp?estudio=13244, consultado el 5 de marzo del 2016.

Comisión Europea, 2016, Immigration, Eurostat, disponible en http://ec.europa. eu/eurostat/data/database, consultado el 7/03/2016.

Chami, Ralph, Fullenkamp, Connel y Jahjah, Samir, 2003, Are Immigrant Remittance Flows a Source of Capital for Development? IMF Working Paper WP/03/189, International Monetary Fund, Washington, DC.

Crafts, Nicholas y Toniolo, Gianni (eds.), 1996, Economic Growth in Europe since 1945, Cambridge. Cambridge University Press, Cambridge.

Del Arenal Moyúa, Celestino, 1994, Política exterior de España hacia Iberoamérica, Editorial Complutense, Madrid.

Ferrero Turrión, Ruth y López Sala, Ana María, 2009, "Nuevas dinámicas de gestión de las migraciones en España: el caso de los acuerdos bilaterales de trabajadores con países de origen", en Revista del Ministerio de Trabajo e Inmigración, núm. 80.

Gabrielli, Lorenzo, 2012, "El co-desarrollo y la externalización europea del control migratorio hacia África: Los riesgos de una relación ambigua", en El codesarrollo a debate, Editorial Comares, Granada.

Glytsos, Nicholas P., 2002, "Dynamic effects of migrant remittances on growth: an econometric model with an application to Mediterranean countries", en Centre of Planning and Economic Research, núm. 74.

González, Mariano y Larrú, José María, 2004, ¿A quién benefician los créditos FAD? Los efectos de la ayuda ligada sobre la economía española, Documento de Trabajo Serie Desarrollo y Cooperación, Documento de Trabajo, Serie Desarrollo y Cooperación, Departamento de Desarrollo y Cooperación Instituto Complutense de Estudios Internacionales, Madrid.

Granados, Antolín, 2004, "El tratamiento de la inmigración en la prensa española", en Atlas de la inmigración marroquí en España, Taller de Estudios Internacionales Mediterráneos, Madrid.

Intermón-OXFAM, 2006, La realidad de la ayuda 2006-2007, disponible en PDF en http://www.oxfamintermon.org/sites/default/files/documentos/files/070323_ Realidad_Ayuda_06-07_0.pdf 
Instituto Nacional de Estadística (INE), 2016, Encuesta de la Población Activa, Ocupados por nacionalidad, sexo y sector económico, disponible en http://www. ine.es/jaxiT3/Tabla.htm?t=4133\&L=0, consultado el 7/03/2016.

Izquierdo Escribano, Antonio, López De Lera, Diego y Martínez Buján, Raquel, 2002, "Los preferidos del siglo XXI: la inmigración latinoamericana en España", en La inmigración en España: contextos y alternativas, Universidad de Granada, Laboratorio de Estudios Interculturales, Granada.

Kapur, Devesh, 2005, “Las remesas: ¿el nuevo mantra del desarrollo?”, en Remesas: su impacto en el desarrollo y perspectivas futuras, Banco Mundial y Mayol Ediciones, Washington, DC.

López Sala, Ana María, 2005, Inmigrantes y Estados: la respuesta política ante la cuestión migratoria, Anthropos Editorial, Barcelona.

Mármora, Lelio, 2002, Las políticas de migraciones internacionales, Paidós, Buenos Aires.

MAEC, 2005, Plan Director de la Cooperación Española 2005-2008, MAEC, Ministerio De Asuntos Exteriores y Cooperación, Madrid.

Ministerio de Empleo y Seguridad Social, 2016a, Extranjeros con certificado de registro o tarjeta de residencia en vigor, disponible en http://extranjeros.empleo. gob.es/es/Estadisticas /, consultado el 7/03/2016.

Ministerio de Empleo y Seguridad Social, 2016b, Trabajadores extranjeros afiliados a la seguridad social en alta laboral, disponible en https://explotacion.mtin. gob.es/series/, consultado el 7/03/2016.

Ministerio de Trabajo e Inmigración, 2009, Anuario Estadístico de Inmigración 2008, Ministerio de Trabajo e Inmigración, Madrid.

Moreno Fuentes, Francisco Javier y Bruquetas Callejo, María, 2011, Inmigración y Estado de bienestar en España, Obra Social "la Caixa", Barcelona.

OCDE, 2016, Flux par fournisseur et bénéficiaire, Organización para la Cooperación y el Desarrollo Económico, disponible en http://stats.oecd.org/, consultado el 9/03/2016.

Pinyol, Gemma, 2007, "España en la construcción del escenario euroafricano de migraciones”, en Revista CIDOB d'Afers Internacionals, núm. 79-80.

Romero, Eduardo, 2008, “El Plan África, la política migratoria española de 'nueva generación' y la guerra contra los pobres", en Frontera Sur. Políticas de control y externalización de la inmigración en Europa, Virus editorial, Barcelona.

Sánchez-Montijano, Elena y Faúndez-García, Rocío, 2011, "Migración laboral temporal y circular y codesarrollo: estudio de caso de una articulación posible", en Migraciones, núm. 30.

Sassen, Saskia, 1988, The Mobility of Capital and Labor: A Study in International Investment and Labor Flow, Cambridge University Press, Cambridge.

Sebastián, Miguel, 2006, Inmigración y economía española: 1996-2006, Informe de la Oficina Económica del Presidente, Madrid. 
Seers, Dudley, 1981, "La periferia europea”, en La Europa subdesarrollada. Estudios sobre las relaciones Centro-Periferia, $\mathrm{H}$. Blume Ediciones, Madrid.

Tedesco, Laura, 2010, "Inmigración y política exterior: desafíos frente a la crisis económica”, en FRIDE Policy Brief, núm. 22.

United Nations, 2013, Trends in international migrant stock: migrants by destination and origin, Department of Economic and Social Affairs, Department of Economic and Social Affairs, United Nations database, POP/DB/MIG/Stock/ Rev.2013, consultado el 11/03/2016.

United Nations, 2016, Bilateral Statistics, Conference on Trade and Development, UNCTAD, disponible en http://unctad.org/en/Pages/DIAE/FDI\%20Statistics/ FDI-Statistics-Bilateral.aspx, consultado el 11/03/2016.

Verdugo Matés, Rosa María y Villasante, Sebastián, 2012, "Vulnerabilidad y efectos migratorios de la sobreexplotación de recursos marinos en África: el caso de estudio de Senegal", en XIII Coloquio Ibérico de Geografía: Respuestas de la Geografía Ibérica a la crisis actual, Asociación de Geógrafos Españoles, Santiago de Compostela.

Verdugo Matés, Rosa María, Pereira López, Xesús y César Vila, Manuel, 2015, "La contribución de la inmigración al crecimiento económico en los países de la Unión Europea de los 15”, en II Congreso Internacional SETED, Santiago de Compostela.

Wallerstein, Immanuel, 1974, The Modern World-System, vol. I: Capitalist Agriculture and the Origins of the European World-Economy in the Sixteenth Century, University of California Press, New York, London.

\section{RESUMEN CURRICULAR DE LA AUTORA}

\section{Rosa María Verdugo Matés}

Es Doctora en Ciencias Económicas y Empresariales por la Universidad de Santiago de Compostela. Desde el año 2015 es Investigadora Asociada en Les Afriques dans le Monde (LAM), Instituto de Estudios Políticos de la Universidad de Burdeos (Francia). Desde el año 2002 centra sus investigaciones en la temática de las migraciones. Entre las principales publicaciones en este ámbito destacan: $O$ contributo dos imigrantes na economia espanhola e nos paises de orige durante o último ciclo de crecimento económico (2016); Las remesas enviadas desde España: análisis de su impacto en las economías receptoras (2014); Flujos migratorios y económicos entre Europa y África Occidental (2013).

Dirección electrónica: rosa.verdugo@usc.es

Artículo recibido el 29 de abril de 2016 y aprobado el 26 de junio de 2017. 